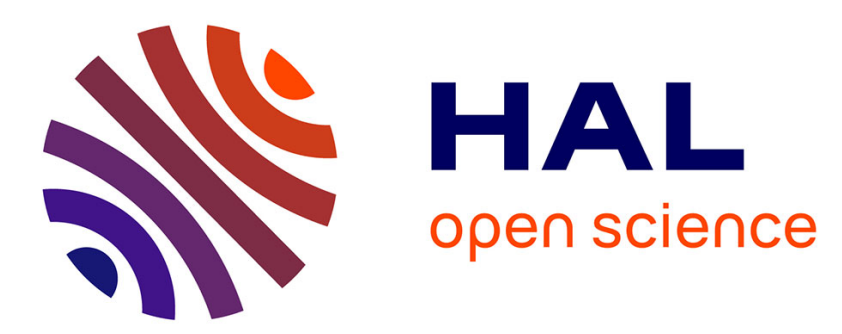

\title{
Assimilation of satellite altimetry referenced to the new GRACE geoid estimate
}

\author{
Florence Birol, J. M. Brankart, J. M. Lemoine, P. Brasseur, J. Verron
}

\section{To cite this version:}

Florence Birol, J. M. Brankart, J. M. Lemoine, P. Brasseur, J. Verron. Assimilation of satellite altimetry referenced to the new GRACE geoid estimate. Geophysical Research Letters, 2005, 32 (6), pp.WOS:000227874400002. 10.1029/2004GL021329 . hal-00409271

\section{HAL Id: hal-00409271 \\ https://hal.science/hal-00409271}

Submitted on 19 Feb 2021

HAL is a multi-disciplinary open access archive for the deposit and dissemination of scientific research documents, whether they are published or not. The documents may come from teaching and research institutions in France or abroad, or from public or private research centers.
L'archive ouverte pluridisciplinaire HAL, est destinée au dépôt et à la diffusion de documents scientifiques de niveau recherche, publiés ou non, émanant des établissements d'enseignement et de recherche français ou étrangers, des laboratoires publics ou privés. 


\title{
Assimilation of satellite altimetry referenced to the new GRACE geoid estimate
}

\author{
F. Birol, ${ }^{1}$ J. M. Brankart, ${ }^{1}$ J. M. Lemoine, ${ }^{2}$ P. Brasseur, ${ }^{1}$ and J. Verron ${ }^{1}$ \\ Received 20 August 2004; revised 29 October 2004; accepted 9 December 2004; published 18 March 2005.
}

[1] Currently, two satellite gravimetric missions (CHAMP, GRACE) are dedicated to the improvement of our knowledge of the geoid, and one (GOCE) is planned in the near future. This will allow the absolute altimeter ocean height measurements to be exploited, instead of only sea level variations. In this paper, we evaluate the impact of the GRACE mission on ocean data assimilation. The new approach is to directly assimilate the full altimetric signal relative to the first release of a GRACE geoid. The response of an eddy-permitting ocean model of the North Atlantic to the assimilation of this altimetric signal is analysed. The results are compared to that obtained using the usual approach, i.e., the assimilation of the dynamic topography derived from the addition of altimetric sea level anomalies and a mean dynamic topography estimate. Even if the GRACE mission resolution (333 km) is not yet compatible with oceanographic studies at mid latitude, we show that the geoid estimate can already be used with success in basin scale altimetric data assimilation problems. Citation: Birol, F., J. M. Brankart, J. M. Lemoine, P. Brasseur, and J. Verron (2005), Assimilation of satellite altimetry referenced to the new GRACE geoid estimate, Geophys. Res. Lett., 32, L06601, doi:10.1029/2004GL021329.

\section{Introduction}

[2] The sea surface height measured by altimeter satellites is the sum of (i) the geoid $(G)$ with respect to a chosen reference ellipsoid and (ii) the ocean dynamic topography (DT). Only the latter is relevant for oceanographic applications. Unfortunately, up to now, geoid uncertainties were too large, on the scale of important ocean circulation features, to deduce directly the dynamic topography from altimetry. Altimetric applications have concentrated on ocean variability, through the analysis of sea level anomalies (SLA). Absolute dynamic topography has only been accessible by the addition of a mean dynamic topography estimate (MDT) to the SLA [see Birol et al., 2004, Figure 4]. A variety of methods have been applied to generate different MDT products used in ocean prediction systems [Le Grand et al., 1998; Rio and Hernandez, 2004]. Birol et al. [2004] showed that errors in such MDT estimates have an important impact on assimilation systems.

[3] Several geodetic missions such as CHAMP and GRACE, respectively launched in 2000 and 2002, and the

\footnotetext{
${ }^{1}$ Laboratoire des Ecoulements Geophysique et Industriels, Grenoble, France.

${ }^{2}$ Centre National d'Etudes Spatiales/Groupe Recherches de Géodésie Spatiale, Toulouse, France.

Copyright 2005 by the American Geophysical Union. 0094-8276/05/2004GL021329
}

European Space Agency GOCE program scheduled for 2006, are dedicated to providing a precise estimate of the ocean geoid (10 cm error) at high spatial resolution $(80 \mathrm{~km})$. Several studies have recently concluded on the improvement expected from these missions, in many fields of concern [Schröter et al., 2002]. The objective of the present work is to evaluate the impact of using a "state of the art" geoid derived from GRACE satellite data as the reference surface for altimetric assimilation into an eddy-resolving model. The results are compared to a second experiment where SLA added to a synthetic MDT derived from in situ observations (as in section 2) are assimilated. Both solutions are compared in terms of circulation and transport, focusing on the North Atlantic. The simulated thermal content is validated with independent XBTs.

\section{The Dynamic Topography Computation}

[4] The satellite estimation of the dynamic topography (named DT1 hereafter) used in this study was computed by subtracting a satellite-only derived geoid from satellite sea surface height (SSH) observations:

$$
\mathrm{DT} 1=\mathrm{SSH}-\mathrm{G} .
$$

The geoid was computed from the EIGEN-GRACE01S Earth gravity field model, released on July 2003 and based on 39 days of GRACE satellite data gathered between August and November 2002. This time span being short and the short spatial scales therefore noisy, the expansion of the geoid was limited to spherical harmonic degree $60(333 \mathrm{~km})$ and a progressive spatial filter was applied between degrees 30 and 60. This model is 5 times more accurate than the latest CHAMP field and about 50 times more accurate than the pre-CHAMP satellite-only gravity models (at $1000 \mathrm{~km}$ half wavelength). The cumulated error (Figure 1) is $1.2 \mathrm{~cm}$ at harmonic degree 60 and $42 \mathrm{~cm}$ at harmonic degree 120 $(166 \mathrm{~km})$.

[5] We also compute a classical dynamic topography (DT2), as the sum of satellite SLA, and a MDT product:

$$
\mathrm{DT} 2=\mathrm{SLA}+\mathrm{MDT} .
$$

The latter is obtained at $1^{\circ}$ resolution [Le Grand et al., 1998] by a non-linear inverse model of the North Atlantic general circulation constrained by a compilation of 70 years of hydrographic data and altimetric observations over 1993-1996. This approach is based on dynamical considerations but limited by resolution and accuracy of available data.

[6] In addition to possible errors in the inverse procedure when computing the synthetic MDT, the main drawback of the DT2 method is using a mean topography to derive SLA 


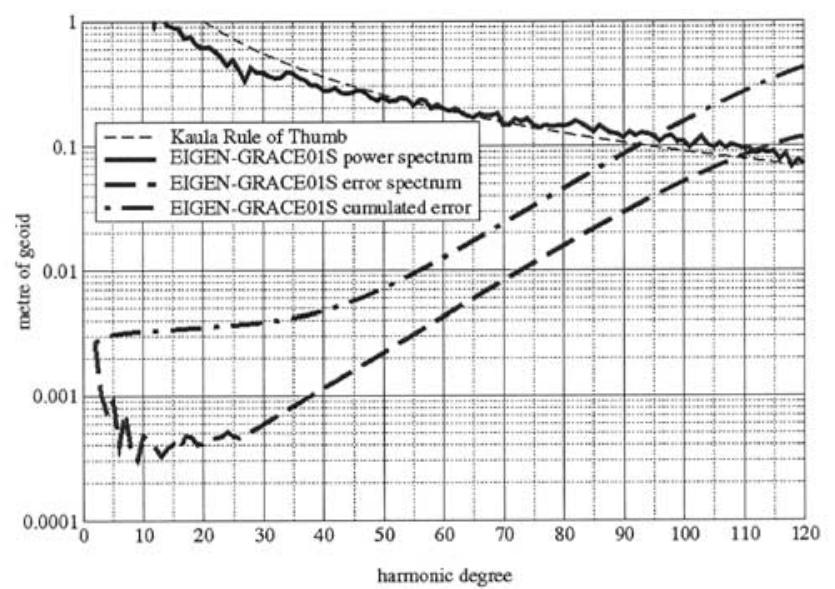

Figure 1. Spectral power (amplitude per degree) and associated formal error estimation for the EIGENGRACE01S geoid.

from sea surface observations. Our mean sea surface corresponds to a 7-year mean (1993-1999) of altimetric data. This averaging period should, in principle, also be used to compute the MDT, but this would have limited the number of available observations to constrain the inverse problem. In DT1, we avoid errors related to such an averaging period because the geoid variability is 3 orders of magnitude lower than the sea surface topography variability. If we exclude the altimeter errors, only the low resolution of the geoid can be a limiting factor for using DT1. The satellite altimetric data consist of TOPEX/Poseidon and ERS1-2. Both DT1 and DT2 are defined along track.

\section{Satellite Mean Dynamic Topography and Geostrophic Currents Versus Classical Solutions}

[7] The time average (respectively MDT1 and MDT2) of the two dynamic topographies (DT1 and DT2) is shown on Figure 2. On large scale (>500 km), both MDTs are coherent and show the classical picture of the North and Tropical Atlantic Ocean circulation. In MDT1, both subpolar and subtropical gyre circulations are stronger. Many short scale discrepancies observed over the whole domain illustrate the different MDT resolution. The largest differences are located

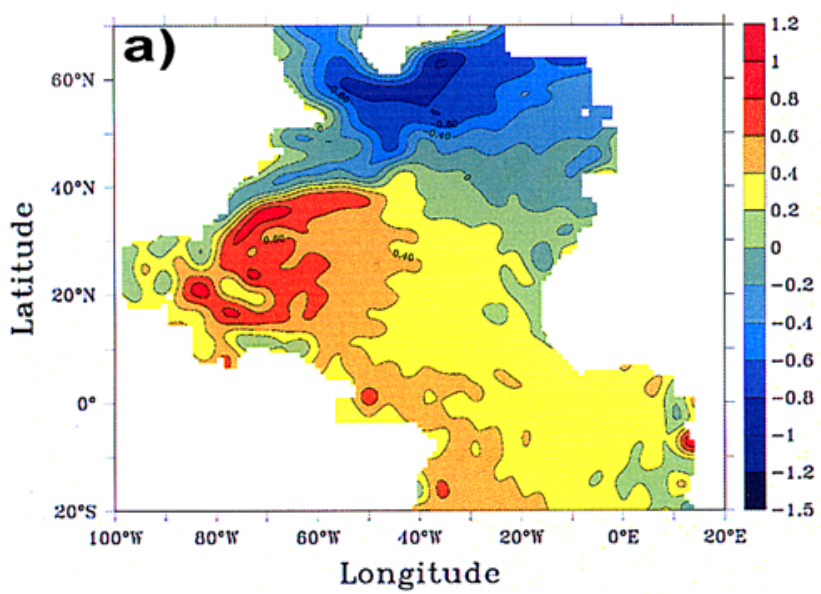

along the fronts associated with the Labrador and East/West Greenland Current system $(15 \mathrm{~cm})$ and associated with the Gulf Stream Current (GSC) Extension $(25 \mathrm{~cm})$. They are mostly due to the different MDT resolution and to the more south GSC front position in MDT1. Important discrepancies are also located along the boundaries, due to significant errors in MDT1 close to the coast (no mask was applied on land in the geoid calculation).

[8] Monitoring the surface currents is crucial for many operational applications. Calculating the mean surface currents is a stringent test for the satellite DT1. Figure 3 represents the North Atlantic mean surface geostrophic currents magnitude deduced from MDT1 and MDT2. Some unrealistic currents (around $5 \mathrm{~cm} / \mathrm{s}$ ) are observed near the coast in Figure 3a, due to coastal errors in the geoid. The classical surface currents are clearly visible. Both solutions are in accordance on the magnitude of some currents: the North Atlantic Current (NAC) with a value of $15 \mathrm{~cm} / \mathrm{s}$ and the Azores Current with a value of $5 \mathrm{~cm} / \mathrm{s}$. Significant differences are also observed: the Florida Current (FC) and the GSC with a value of $30 \mathrm{~cm} / \mathrm{s}(50 \mathrm{~cm} / \mathrm{s})$ for DT1 (DT2), the GSC Extension with a value of $25 \mathrm{~cm} / \mathrm{s}(20 \mathrm{~cm} / \mathrm{s})$ for DT1 (DT2), and the Labrador and East/West Greenland Current system with a value of $10-15 \mathrm{~cm} / \mathrm{s}(5 \mathrm{~cm} / \mathrm{s})$ for DT1 (DT2). Even with a lower resolution, the DT1 satellite solution provides similar mean geostrophic currents amplitude to those from DT2.

\section{The Assimilation System}

[9] This study is based on the assimilation system described in detail by Birol et al. [2004]. The circulation model is HYCOM, the HYbrid Coordinate Ocean Model [Bleck, 2002]. The computational domain is the North and Tropical Atlantic Ocean basin from $28^{\circ} \mathrm{S}$ to $70^{\circ} \mathrm{N}$ at eddypermitting grid resolution of $1 / 3^{\circ} \times 1 / 3^{\circ} \cos (\phi)$, where $\phi$ is the latitude. The vertical density structure consists of 26 layers. The boundaries are closed and relaxed to the climatology. The model is initialised with the Levitus climatology and is then spun up during 9 years, before running a 1985-1996 interannual experiment. The sea surface salinity (SSS) and temperature (SST) are relaxed to the Levitus monthly climatology. High frequency (every 6 hours) ECMWF atmospheric forcing is used.

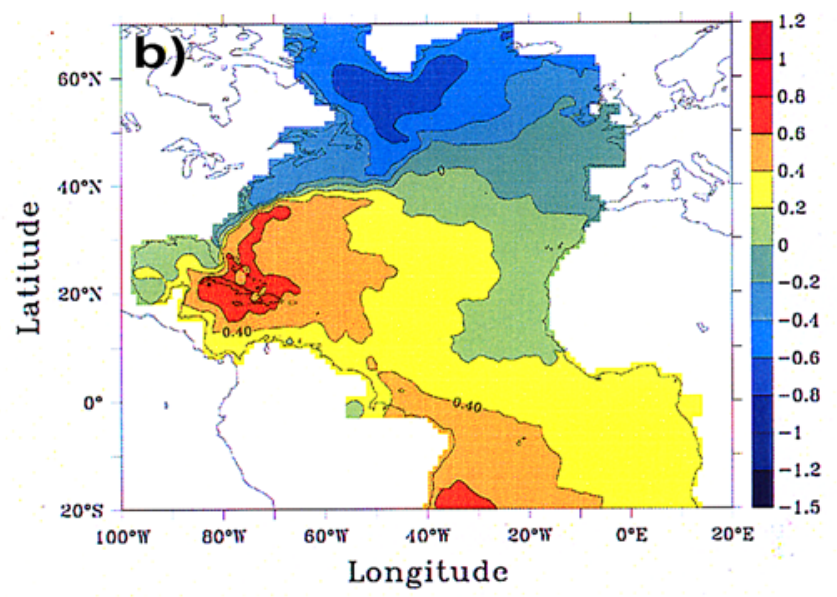

Figure 2. Mean Dynamic Topography (in meters). a) MDT1 and b) MDT2. 


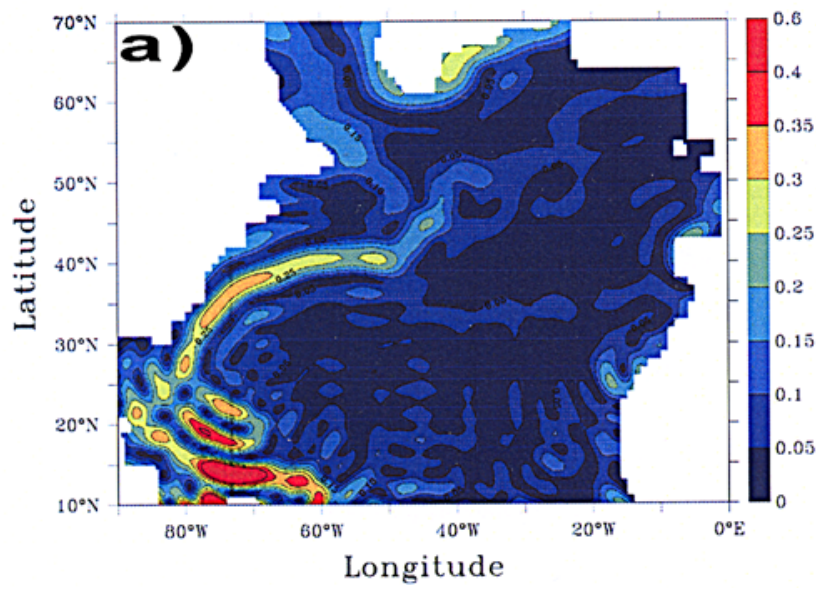

Figure 3. Geostrophic currents magnitude (m/s) deduced from a) MDT1 and b) MDT2.

[10] The assimilation method is based on a reduced order Kalman filter, derived from the SEEK filter [Pham et al., 1998]. The estimation vector consists of the interface pressure, temperature, salinity, and the sea surface height. The gain is local, i.e., the control of a specified water column will only depend on observations within a specified influence bubble $\left(5^{\circ}\right.$ longitude wide). The forecast error covariance is assumed constant and the assimilation window is 3 days.

[11] The assimilated observation data set is multivariate, including altimetry (DT1 or DT2), SST and SSS. SST are high-resolution AVHRR maps. SSS are monthly climatological data. We introduce a low-pass filter in the model SSS observation operator to influence only large-scale corrections with the smooth climatological SSS. In the assimilation system, a bulk error of $3 \mathrm{~cm}, 0.4^{\circ} \mathrm{C}$ and 0.05 PSU RMS has been prescribed on, respectively, sea surface height, SST and SSS observations. A validation of the assimilation system used for this study can be found in Brankart et al. [2003] and Birol et al. [2004].

\section{Sensitivity Study}

[12] DT1 and DT2 are used to perform two assimilation experiments between October 1992 and December 1993 (named, respectively, EXP1 and EXP2). The initial condi-

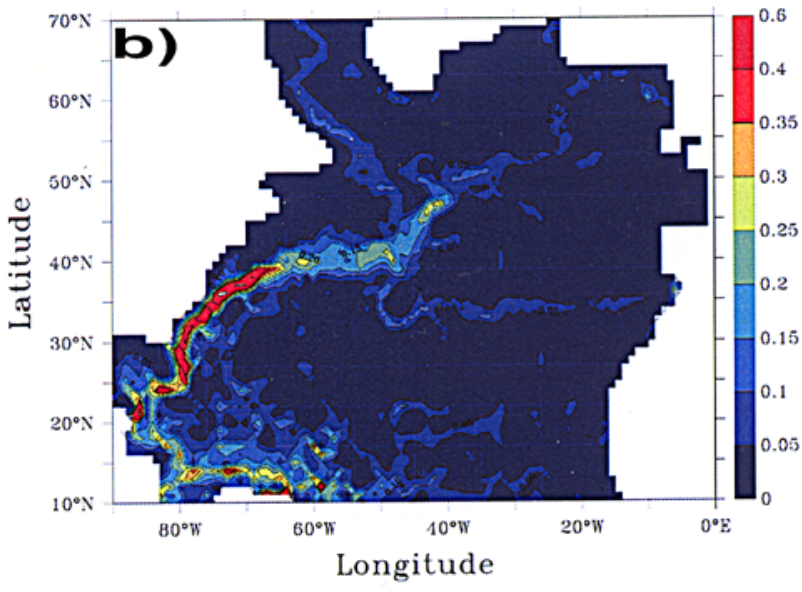

tion and forcing fields are the same. Various diagnostics calculated from 3-day forecasts over 1993 are presented.

\subsection{Surface Currents and Transport}

[13] Figure 4 shows the 1993 mean currents at $50 \mathrm{~m}$ depth for the 2 simulations. The assimilation process has changed the mean surface currents (see Figure 3). On Figure 4, differences are observed mainly in current magnitude. The mean FC flow is $60 \mathrm{~cm} / \mathrm{s}$ in both EXP1 and EXP2, which is still too weak [Frankignoul et al., 2001]. The GSC velocities are more realistic in EXP2 west of $65^{\circ} \mathrm{W}$ (with a maximum of $1 \mathrm{~m} / \mathrm{s}$ at Cape Hatteras instead of $60 \mathrm{~cm} / \mathrm{s}$ in EXP1), whereas they are in better agreement with observations in EXP1 east of this longitude $(30 \mathrm{~cm} / \mathrm{s}$ instead of $20 \mathrm{~cm} / \mathrm{s}$ in EXP2). Downstream Cape Hatteras, an unrealistic weak northern branch of the GSC appears in EXP1 along the shelf, due to the lack of resolution in DT1 near the coast of Cape Hatteras. The progressive widening of the GSC flow along its path is stronger in EXP2. This is also consistent with the geostrophic solution (Figure 3). The GSC and NAC pathway is $1-2^{\circ}$ further north in EXP1, where the maximum gradient of DT1 is located. The EastWest Greenland/Labrador Current system is particularly weak in EXP2 $(5 \mathrm{~cm} / \mathrm{s})$. In EXP1, this system reaches a much more realistic value of $15-20 \mathrm{~cm} / \mathrm{s}$ [Cuny et al., 2002].

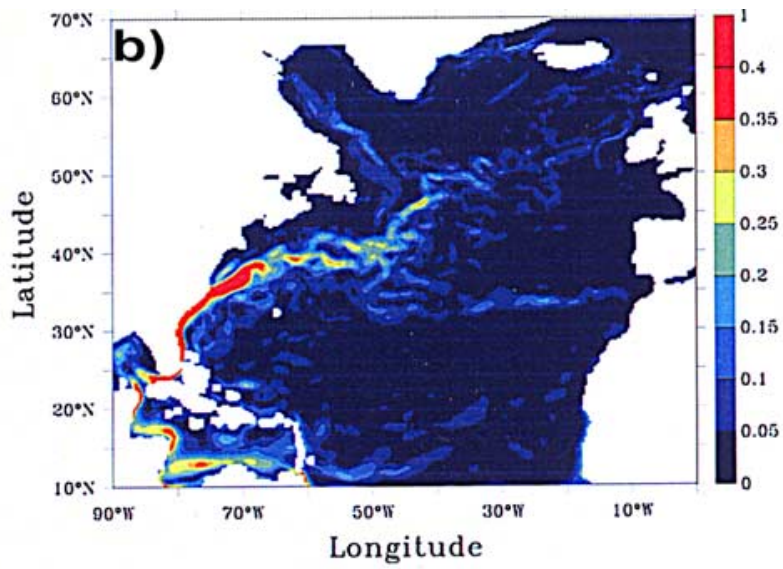

Figure 4. Mean surface currents velocity (m/s) for a) EXP1 and b) EXP2. 

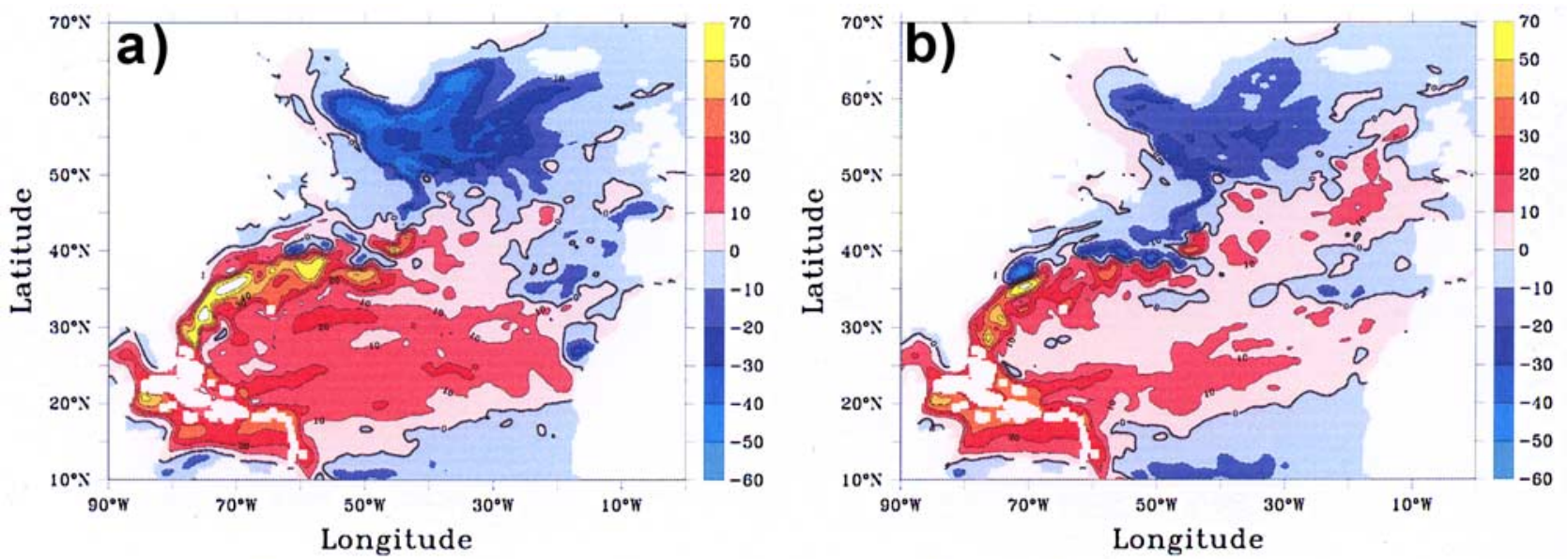

Figure 5. Mean barotropic stream function for a) EXP1 and b) EXP2.

[14] The assimilation process also changes the vertical circulation structure. The vertically integrated horizontal circulation pattern is represented by the mean barotropic stream function (Figure 5) for EXP1 and EXP2. Both results show well-developed subpolar and subtropical gyres. In EXP1, the transport is $20 \mathrm{~Sv}$ higher than in EXP2, for both the subtropical $(40-50 \mathrm{~Sv})$ and the subpolar $(30-40 \mathrm{~Sv})$ gyres. The values obtained with EXP1 are more realistic.

\subsection{Comparison With Independent TS Profiles}

[15] To further analyse the results, we have compared the forecasted model thermal field from each experiment to an ensemble of XBT profiles collected in the North Atlantic over 1993 (IFREMER database).

[16] RMS misfit between the XBTs and the closer equivalent model state for the Gulf Stream region are shown on Figure 6. The black curve is the result obtained by the control run (without assimilation), the red curve for EXP1, the green curve for EXP2, the blue curve is obtained by comparing the climatology and the XBTs.

[17] In the Gulf Stream region, both EXP1 and EXP2 are closer than the free run to XBTs down to a depth of at least $550 \mathrm{~m}$. However, EXP2 still shows better results than EXP1, with misfits remaining better than the free run down

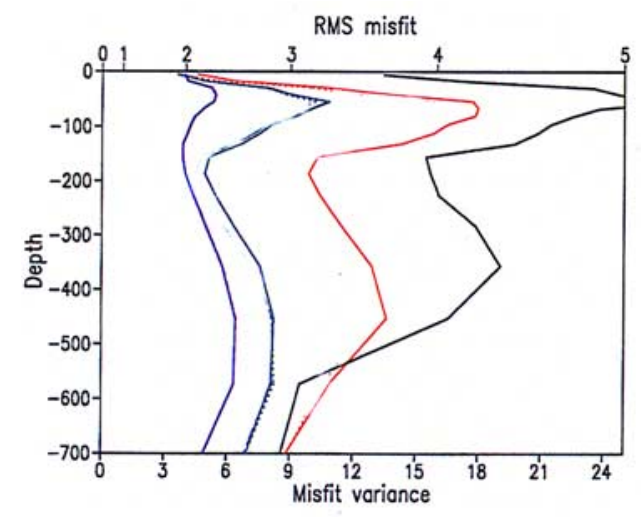

Figure 6. Temperature RMS misfit $\left({ }^{\circ} \mathrm{C}\right)$ with respect to XBT profiles in the Gulf Stream region, down to $700 \mathrm{~m}$ and averaged for 1993: free run (black), EXP1 (red), and EXP2 (green) and climatology (blue). to a depth of $700 \mathrm{~m}$. In the GS front region, the results are particularly sensitive to the dynamic topography used in the simulation, since strong corrections are applied by the assimilation. The rms difference between EXP1 and EXP2 is mainly due to a northward shift of the isotherms in EXP1, due to a misplaced GS front. The frontal characteristics of the GSC can have length scales ranging from 100 to $230 \mathrm{~km}$, not yet resolved by the GRACE geoid. At high latitudes, EXP1 and EXP2 results are similar (not shown).

\section{Summary and Conclusion}

[18] Altimetric data, which contain excellent information about the ocean mesoscale variability, form the common backbone of all basin-scale ocean assimilation systems. However, the assimilation of the full altimetric signal requires an accurate estimate of the geoid in order to provide a geopotential reference for the observed sea surface height. The accuracy of the geoid directly determines the accuracy of the assimilated mean dynamic topography.

[19] We show that a satellite geoid computed with the first GRACE data can already be used with some success for basin-scale altimetric data assimilation problems. Even if this geoid does not resolve short wavelengths $(<330 \mathrm{~km})$, which constitutes a drawback for oceanic studies at mid latitudes, we show that the corresponding simulated flow reaches a degree of accuracy that is already similar to that obtained by the assimilation of SLA added to a typical MDT estimate. In that respect these results are very promising, particularly since the GRACE gravity field models are in fast progress: in one year their accuracy at short wavelengths has been improved by a factor three.

[20] Acknowledgments. This work was conducted within the framework of the TOPAZ project (Grant EVK3-2000-00601). We thank Eric Chassignet for providing the model, the GFZ for the GRACE-EIGEN01S geoid and Pascal Legrand for his MDT field.

\section{References}

Birol, F., J. M. Brankart, F. Castruccio, P. Brasseur, and J. Verron (2004), Impact of the mean dynamic topography on mutivariate data assimilation hindcast, J. Mar. Geod., 27, 59-78.

Bleck, R. (2002), An oceanic general circulation model framed in hybrid isopycnic-cartesian coordinates, Ocean Modell., 4, 55-88.

Brankart, J., C. Testut, P. Brasseur, and J. Verron (2003), Implementation of a multivariate data assimilation scheme for isopycnic coordinate ocean models: Application to a 1993-1996 hindcast of the North Atlantic 
Ocean circulation, J. Geophys. Res., 108(C3), 3074, doi:10.1029/ 2001JC001198.

Cuny, J., P. B. Rhines, P. P. Niiler, and S. Bacon (2002), Labrador Sea boundary currents and the fate of the Irminger Sea Water, J. Phys. Oceanogr., 32, 627-647.

Frankignoul, C., et al. (2001), Gulf Stream variability and ocean-atmosphere interactions, J. Phys. Oceanogr., 31, 3516-3529.

Le Grand, P., et al. (1998), Combining T/P altimetric data with hydrographic data to estimate the mean dynamic topography of the North Atlantic and improve the geoid, Ann. Geophys., 16, 638-650.

Pham, D. T., J. Verron, and M. C. Roubaud (1998), Singular evolutive extended Kalman filter with EOF initialization for data assimilation in oceanography, J. Mar. Syst., 16, 323-340.

Rio, M.-H., and F. Hernandez (2004), A mean dynamic topography computed over the world ocean from altimetry, in situ measurements, and a geoid model, J. Geophys. Res., 109, C12032, doi:10.1029/ 2003JC002226.

Schröter, J., M. Losch, and B. Sloyan (2002), Impact of the Gravity Field and Steady-State Ocean Circulation Explorer (GOCE) mission on ocean circulation estimates: 2. Volume and heat fluxes across hydrographic sections of unequally spaced stations, J. Geophys. Res., 107(C2), 3012, doi:10.1029/2000JC000647

F. Birol, J. M. Brankart, P. Brasseur, and J. Verron, Laboratoire des Ecoulements Geophysique et Industriels, BP53, F-38041 Grenoble Cedex 9, France. (florence.birol@notos.cst.cnes.fr)

J. M. Lemoine, Centre National d'Etudes Spatiales/Groupe Recherches de Géodésie Spatiale, 18 av. E. Belin, F-31401 Toulouse Cedex 4, France. 